\title{
Protective Effects of Sugar Cane Extracts (SCE) on Eimeria tenella Infection in Chickens
}

\author{
Moshira EL-ABASY ${ }^{1,2)}$, Maki MOTOBU ${ }^{2)}$, Ki-Jeong NA ${ }^{2,3)}$, Kameo SHIMURA ${ }^{2)}$, Kikuyasu NAKAMURA ${ }^{2)}$, \\ ${\text { Kenji } \mathrm{KOGE}^{4} \text {, Takashi ONODERA }}^{1)}$ and Yoshikazu HIROTA ${ }^{2) *}$ \\ ${ }^{1)}$ Department of Molecular Immunology, Graduate School of Agricultural and Life Sciences, The University of Tokyo, 1-1-1 Yayoi, \\ Bunkyo-ku, Tokyo 113-8657, ${ }^{2)}$ National Institute of Animal Health, National Agricultural Research Organization, 3-1-5 Kannondai, \\ Tsukuba, Ibaraki 305-0856, Japan, ${ }^{3)}$ College of Veterinary Medicine, Chungbuk National University, 48 Gaesindong, Cheongju 361-763, \\ Republic of Korea and ${ }^{4)}$ Chigasaki Laboratory, Shin Mitsui Sugar Co., Ltd., 1-2-14 Honson, Chigasaki, Kanagawa 253-0042, Japan
}

(Received 3 February 2003/Accepted 8 April 2003)

ABSTRACT. The effects of oral administration of sugar cane extracts (SCE) on Eimeria tenella oocysts infection in chickens were studied with 2 different experiments. In Experiment 1, 3-week-old inbred chickens (MHC; H.B15) were inoculated into the crop with SCE (500 $\mathrm{mg} / \mathrm{kg} / \mathrm{day})$ for 1 day or 3 consecutive days, and then challenged with E. tenella sporulated oocysts $\left(2 \times 10^{4}\right.$ cells/chicken). In Experiment 2, 1-week-old chickens were orally administered SCE at the same dose for 3 consecutive days, and then initially infected with $E$. tenella sporulated oocysts $\left(2 \times 10^{3}\right.$ cells/chicken). At 2 and 3 weeks of age, these chickens were immunized intravenously with the mixed antigens of sheep red blood cells (SRBC) and Brucella abortus (BA). At 4 weeks of age, chickens were challenged with E. tenella sporulated oocysts $\left(1 \times 10^{5} /\right.$ chicken). Challenged chickens with $E$. tenella oocysts showed markedly decreased body weight gain/day, severe hemorrhage and great number of shedding oocysts in feces and high lesion scores. Oral administration of SCE and initial infection with oocysts $\left(2 \times 10^{3}\right.$ /chicken) resulted in a remarkable improvement in body weight gain/day, hemorrhage, the number of shedding oocysts and lesion score, compare to other infected groups. In addition, SCE-inoculated chickens with the initial infection showed a significant increase in antibody responses against SRBC and BA and also improvement in decreased relative proportions of Bu- $1 \mathrm{a}^{+}$and CD4 cells in cecal tonsil lymphocytes of E. tenella-challenged chickens. Cecal tissues of chickens administered SCE and initially infected with $E$. tenella oocysts showed lower numbers of schizonts, gametocytes and oocysts than those of infected control chickens. These results suggest that SCE have immunostimulating and protective effects against $E$. tenella infection in chickens.

KEY WORDS: Eimeria tenella, protective effect, sugar cane extract.

Chicken coccidiosis is caused by obligate intestinal protozoan parasites belonging to several different species of Eimeria. Eimeria tenella (E. tenella) primarily invades and resides in the lining of the cecum of exposed chickens [1, 14, 27-30]. Infective sporozoits enter the cecal mucosa by penetrating villus epithelial cells, resulting in extensive destruction of the cecal epithelium, hemorrhagic feces, reduction in body weight gain, and decrease in feed efficiency and eventual mortality which lead to serious economic consequences. Thus far, chemoprophylaxis and anticoccidial feed additives have controlled the disease but have been complicated by the emergence of drug resistance $[4,12,26]$.

To prevent the emergence of drug resistance, new drugs have been developed and administered on a rotational basis with existing drugs. However, this has resulted in the increased cost of poultry products. Furthermore, drug or antibiotic residue in the poultry products is potentially annoyance to consumer. Therefore, the regulation of anticoccidial drugs should be strengthened gradually. It is generally agreed that protective immunity does not block sporozoites from penetrating the intestinal epithelium, but it

\footnotetext{
* Correspondence to: Hirota, Y., Department of Production Diseases, National Institute of Animal Health, National Agricultural Research Organization, 3-1-5 Kannondai, Tsukuba, Ibaraki 305-0856, Japan.
}

is not clear to what extent immune response to E. tenella sporozoites in the gut lumen can block penetration. Chickens orally administered attenuated vaccine or infected with a small number of E. tenella oocysts were shown to be resistant against challenge infection with the sublethal number of the same parasite.

Immunomodulators are a highly expanding field of studies to compete and/or control infectious diseases. Sugar cane extracts (SCE), one of native immunostimulants, have been reported to enhance immune responses, immune functions and growth in chickens $[5,6]$. In immune chickens only a few sporozoites reach the cecal epithelium during reinfection and those are unable to develop further $[22,23$, 27]. The purpose of the present study is to explore the feasibility of immunological protection of chickens against $E$. tenella infection by oral administration of SCE and initial infection with $E$. tenella oocysts.

\section{MATERIALS AND METHODS}

Animals: Inbred chickens (MHC; H.B15), maintained at the National Institute of Animal Health (NIAH), Tsukuba, Japan, were reared coccidia-free with free access to food and water.

Feed: Experimental feed without antibiotics and anticoccidial food additives was obtained from food manufacture 
company (Sugiji Co., Ltd., Handa, Japan).

Parasite and infection: Eimeria tenella (E. tenella), the NIAH strain, was used. The strain was originally isolated from naturally infected birds and maintained at the NIAH, Tsukuba, Japan.

SCE administration: Original materials of SCE including cane juice produced from sugar cane (Saccharum officinarum L.) in the raw sugar manufacturing process were subjected to the preparation of SCE (Shin Mitsui Sugar Co., Ltd., Japan) as described earlier [5, 6]. The original concentration of SCE $(100 \mathrm{mg} / \mathrm{m} l)$ was prepared in phosphate buffered saline (PBS). SCE was inoculated with a pipette (Komagome pipet, Iwaki Co., Tokyo, Japan) into the crop of chickens at the dose of $500 \mathrm{mg} / \mathrm{kg} /$ day for 1 day or 3 consecutive days.

Experiment 1: This experiment was carried out to evaluate the effect of SCE on the incidence of coccidiosis in chickens. Three-week-old inbred chickens were divided into 4 groups, 1) uninfected control group (referred to as control), 2) chickens were inoculated into the crop with $E$. tenella oocysts $\left(2 \times 10^{4}\right.$ cells/chicken) (referred to as challenge), 3) chickens orally administered a single dose of SCE $(500 \mathrm{mg} / \mathrm{kg})$ and then challenged with the same dose of $E$. tenella oocysts (referred to as SCE (1) + challenge) and 4) chickens orally administered SCE for 3 consecutive days and then challenged with E. tenella oocysts (referred to as SCE (3) + challenge).

The body weight was measured at days 0 and 7 after challenge. Mortality was recorded and body weight gain per day was calculated. Hemorrhagic feces were observed from day 5 to day 7 post challenge. The total amount of feces was collected from all experimental groups from day 5 to day 7 after challenge for oocyst shedding determination [19]. The oocysts were diluted and counted microscopically in a plankton counter chamber. Total oocyst number was calculated as oocyst count $\times$ dilution factor $\times$ counting chamber volume $\times$ fecal sample volume. On day 7 post challenge all chickens were killed and scored for gross cecal lesions on a scale of 0 to 4 according to the method of Conway [3].

Experiment 2: This experiment was performed to evaluate the effects of SCE on immune responses and infection against $E$. tenella in chickens. First, 1-week-old chickens were divided into three groups of control, initial infection and SCE (3) + initial chickens, which were referred in Experiment 1. Each group consisted of 12 chickens. All chickens were immunized intravenously with the mixed antigens of sheep red blood cells (SRBC) and Brucella abortus (BA) at 2 and 3 weeks of age. Subsequently, at 4 weeks of age after evaluation of antibody responses to SRBC and BA, half chickens in the above three groups were challenged orally with $E$. tenella sporulated oocysts $(1 \times$ $10^{5} /$ chicken), consisting the following six groups; 1) salineadministered uninfected control chickens (control), 2) chickens challenged with $E$. tenella sporulated oocysts $(1 \times$ $10^{5}$ chicken) (challenge), 3) chickens challenged with $E$. tenella sporulated oocysts $\left(2 \times 10^{3} /\right.$ chicken) (initial infection), 4) chickens initially infected and then challenged with
E. tenella oocysts (initial + challenge), 5) chickens administered SCE for 3 consecutive days and then initially infected with E. tenella oocysts (SCE (3) + initial), and 6) chickens administered SCE for 3 consecutive days, initially infected and then challenged with E. tenella oocysts (SCE (3) + initial + challenge). Each group consisted of six chickens. Gain in body weight/day (g/day), clinical signs, oocyst shedding and lesion scores were evaluated in all chickens after challenge at 4 weeks of age.

Immunization and determination of antibody titers: Each chicken was immunized intravenously with $0.1 \mathrm{~m} l$ of mixed antigens containing SRBC $\left(5 \times 10^{8}\right.$ cells $)$ and BA $\left(1 \times 10^{9}\right.$ cells) [8] at 2 and 3 weeks of age. Agglutinin titers against SRBC and BA were evaluated in sera taken at 7 days after each immunization, as described previously [8]. The sera were also treated with $0.2 \mathrm{M}$ 2-mercaptoethanol (ME) to evaluate 2-ME resistant agglutinin titers.

Isolation of intestinal leukocytes: Chicken intestinal leukocytes (IL) were prepared according to the technique of Choi et al. [2]. Briefly, the intestine between the duodenal loop and the region immediately prior to the Meckel's diverticulum was excised, cut longitudinally, and washed 3 times in PBS supplemented with $2 \%$ fetal bovine serum (FBS). Intestinal tissue of each chicken was treated separately, cut into small pieces, and incubated for $10 \mathrm{~min}$ in the same medium supplemented by $10 \mathrm{mM}$ dithiothreitol to eliminate the intestinal mucous membrane. The supernatant was discarded and the small pieces of the intestine were incubated for $20 \mathrm{~min}$ at $37^{\circ} \mathrm{C}$ in PBS containing $1 \mathrm{mM}$ EDTA. Cells in the supernatant were washed and gently pressed through a stainless steel mesh to remove most epithelial cells, dead cells and cellular clusters. Cells were further purified by $60 \%$ percoll density gradient centrifugation at 3,000 rpm for $20 \mathrm{~min}$ at $24^{\circ} \mathrm{C}$ to remove red cells. Cell viability was over $95 \%$ as determined by trypan blue exclusion. The cells were finally suspended to a concentration of $1 \times 10^{6}$ cells $/ \mathrm{m} l$ in $2 \%$ FBS-PBS.

Relative proportions of cells positive for marker antigens: The relative proportions (RP) of cells positive for marker antigens in IL were evaluated the following procedures described by Erf et al. [7]. Briefly, $100 \mu l$ of chicken leukocytes $\left(1 \times 10^{6}\right.$ cells $\left./ \mathrm{m} l\right)$ and $100 \mu l$ of $2 \%$ FBS-PBS were mixed in each well of a 96 -well plate and centrifuged at $2,000 \mathrm{rpm}$ for $1 \mathrm{~min}$ at $4^{\circ} \mathrm{C}$. After 2 times washing, the sedimented cells were supplemented with $100 \mu \mathrm{l}$ of mouseanti-chicken monoclonal antibody specific for Bu-1a, CD4, CD8, TCR1, TCR2 and TCR3 markers, generous gifts of Dr. Olli Vainio, University of Turku, Finland, and then incubated on ice for $30 \mathrm{~min}$. After incubation the cells were washed 2 times with $\%$ FBS-PBS and supplemented with $100 \mu l$ of FITC-conjugated anti-mouse IgG antibody (Zymed, CA, U.S.A.) diluted 1:400 in PBS. The cells were incubated on ice for $30 \mathrm{~min}$, and then washed 2 times with $2 \%$ FBS-PBS. The RP of $\mathrm{Bu}-1 \mathrm{a}^{+}, \mathrm{CD}^{+}, \mathrm{CD}^{+}, \mathrm{TCR} 1^{+}$, $\mathrm{TCR}^{+}$and $\mathrm{TCR}^{+}$cells in IL were evaluated using a flow cytometer (XL, Beckman Coulter Corp, U.S.A.).

Histopathology: On day 7 post challenge cecal tissue 
samples were excised, fixed with neutral buffered formalin $(10 \%)$, and then embedded in paraffin. Approximately 4 $\mu \mathrm{m}$ thick cross sections were excised and stained with hematoxylin and eosin (HE) for histopathological examination [19].

Efficacy of SCE: Efficacy of SCE was evaluated on the basis of mortality, gain in body weight/day, degree of hemorrhagic feces, oocyst count/chicken, lesion scores, immune responses and $\mathrm{RP}$ of $\mathrm{Bu}-1 \mathrm{a}^{+}$and $\mathrm{CD}^{+}$in IL. The mortality was estimated from the number of dead chickens in each infected group. The body weight gain per day was determined from challenge to 1 week post challenge. The extent of hemorrhagic fecal score was assigned corresponding to the degree of hemorrhages in the feces [29]. Oocyst shedding was investigated from day 6 to day 7 post challenge with E. tenella and the lesion score of each group was investigated on day 7 post challenge. The localization of schizonts, gametocytes and oocysts in the cecum was microscopically investigated.

Statistical analysis: The Student's $t$ test was used for statistical significance determination. $P$ values of less than 0.05 were considered to be statistically significant. All data were expressed as mean \pm standard error $(\mathrm{SE})$.

\section{RESULTS}

Clinical signs and lesion scores in Experiment 1: Chickens challenged with E. tenella $\left(2 \times 10^{4}\right)$ showed severe clinical signs such as anorexia, depression, severe and continuous hemorrhages in feces and hemorrhagic feces around the cloaca. The surviving chickens showed retarded growth with decreased body weight gain/day as shown in Table 1. Yellowish-white sausage-like structures in the feces excreted from the cecum could be found. In contrast, chickens orally administered SCE and challenged with oocysts showed no mortality, indicating a significant improvement in the body weight gain/day, milder hemorrhages and less number of oocysts shed in feces and lower lesion scores, when compared to the challenged groups (Table 1).

Immune responses: The results concerning immune responses against SRBC and BA in Experiment 2 are summarized in Table 2. SCE-administration and additional initial infection with $E$. tenella oocysts $\left(2 \times 10^{3}\right)$ resulted in an increase in antibody responses against SRBC and BA in both first and second responses, as compared with those of uninfected control group and initially infected group. In addition, the enhancing effects of SCE were shown in both

Table 1. Effect of oral administration of SCE on body gain, fecal oocyst shedding and lesion score in E. tenella infected chickens (Experiment 1)

\begin{tabular}{|c|c|c|c|c|c|c|c|}
\hline \multirow[t]{2}{*}{ Group } & \multirow[t]{2}{*}{$\begin{array}{l}\text { Number of total } \\
\text { chickens }\end{array}$} & \multirow[t]{2}{*}{$\begin{array}{l}\text { Number of dead } \\
\text { chickens }\end{array}$} & \multirow[t]{2}{*}{$\begin{array}{c}\text { Gain in body } \\
\text { weight }(g / \text { day })^{\text {a) }}\end{array}$} & \multirow[t]{2}{*}{$\begin{array}{l}\text { Hemorrhagic } \\
\text { feces }^{\text {b) }}\end{array}$} & \multicolumn{2}{|c|}{$\begin{array}{l}\text { Oocyst shed/chicken } \\
\qquad\left(\times 10^{6}\right)^{\mathrm{c})}\end{array}$} & \multirow[t]{2}{*}{ Lesion score $^{\mathrm{d})}$} \\
\hline & & & & & Day 6 & Day 7 & \\
\hline Control & 10 & 0 & $10.7 \pm 0.1$ & - & 0 & 0 & 0 \\
\hline Challenge & 12 & 0 & $7.6 \pm 1.2^{*}$ & ++ & 58 & 27 & +4.0 \\
\hline SCE $(1)+$ challenge & 7 & 0 & $8.6 \pm 1.1$ & + & 23 & 16 & +3.8 \\
\hline SCE (3) + challenge & 12 & 0 & $8.9 \pm 0.9 * *$ & + & 16 & 12 & +3.3 \\
\hline
\end{tabular}

a) Mean \pm SE.

b) +: Transient hemorrhage; ++: continuous hemorrhage from day 5 to day 7 post infection.

c) Values represent mean oocyst numbers in pooled feces of each group.

d) Values represent mean lesion scores of each group. ${ }^{*} \mathrm{P}<0.01$, compared to control group, and ${ }^{* *} \mathrm{P}<0.05$, compared to challenge group.

Table 2. Antibody responses to SRBC and BA in chickens orally administered SCE and initially infected with E. tenella oocysts (Experi. ment 2)

\begin{tabular}{|c|c|c|c|c|c|c|c|c|c|c|}
\hline \multirow{4}{*}{ Group } & \multirow{4}{*}{ SCE } & \multirow{4}{*}{$\begin{array}{l}\text { Initial } \\
\text { infection with } \\
\text { oocysts } \\
\left(2 \times 10^{3}\right)\end{array}$} & \multicolumn{8}{|c|}{ Immune responses ${ }^{a)}$} \\
\hline & & & \multicolumn{4}{|c|}{ SRBC } & \multicolumn{4}{|c|}{ BA } \\
\hline & & & \multicolumn{2}{|c|}{ First response } & \multicolumn{2}{|c|}{ Second response } & \multicolumn{2}{|c|}{ First response } & \multicolumn{2}{|c|}{ Second response } \\
\hline & & & $\begin{array}{l}\text { Number of } \\
\text { responders }\end{array}$ & Titer & $\begin{array}{l}\text { Number of } \\
\text { responders }\end{array}$ & Titer & $\begin{array}{l}\text { Number of } \\
\text { responders }\end{array}$ & Titer & $\begin{array}{l}\text { Number of } \\
\text { responders }\end{array}$ & Titer \\
\hline \multirow[t]{2}{*}{ Control } & - & - & $12 / 12$ & $8.0 \pm 0.7$ & $12 / 12$ & $10.3 \pm 0.6$ & $1 / 12$ & $0.4 \pm 0.4$ & $12 / 12$ & $10.8 \pm 1.0$ \\
\hline & & & $12 / 12$ & $(6.0 \pm 0.3)^{b)}$ & $12 / 12$ & $(6.7 \pm 0.5)$ & $0 / 12$ & $(0)$ & $0 / 12$ & $(0)$ \\
\hline \multirow[t]{2}{*}{ Initial infection } & - & + & $12 / 12$ & $7.4 \pm 0.7$ & $12 / 12$ & $10.2 \pm 0.9$ & $1 / 12$ & $0.2 \pm 0.2$ & $12 / 12$ & $10.7 \pm 0.7$ \\
\hline & & & $12 / 12$ & $(5.8 \pm 0.2)$ & $12 / 12$ & $(7.9 \pm 0.4)$ & $0 / 12$ & (0) & $0 / 12$ & $(0)$ \\
\hline \multirow{2}{*}{ SCE (3) + initial } & + & + & $12 / 12$ & $12.2 \pm 1.0 * *$ & $12 / 12$ & $13.6 \pm 0.7^{*}$ & $4 / 12$ & $2.6 \pm 1.0^{*}$ & $12 / 12$ & $13.8 \pm 1.0$ \\
\hline & & & $12 / 12$ & $(8.3 \pm 0.5)^{* *}$ & $12 / 12$ & $(11.1 \pm 0.6)^{* *}$ & $0 / 12$ & (0) & $0 / 12$ & (0) \\
\hline
\end{tabular}

a) Mean \pm SE of $\log _{2}$ of the reciprocal antibody titer.

b) The parenthesis show 2-ME resistant titers.

$* \mathrm{P}<0.05 ; * * \mathrm{P}<0.01$, compared to control and initially infected groups, respectively. 
Table 3. Mortality rate, gain in body weight, fecal oocyst shedding and lesion score in chickens orally administered SCE and infected with E. tenella oocysts (Experiment 2)

\begin{tabular}{|c|c|c|c|c|c|c|c|c|c|}
\hline \multirow[b]{2}{*}{ Group } & \multirow[b]{2}{*}{ SEC } & \multicolumn{2}{|c|}{ E. tenella } & \multirow{2}{*}{$\begin{array}{c}\text { Number of } \\
\text { total } \\
\text { chickens }\end{array}$} & \multirow{2}{*}{$\begin{array}{c}\text { Numberof } \\
\text { dead } \\
\text { chickens }\end{array}$} & \multirow{2}{*}{$\begin{array}{c}\text { Gain in body } \\
\text { weight } \\
(\mathrm{g} / \text { day })^{\mathrm{a})}\end{array}$} & \multirow{2}{*}{$\begin{array}{l}\text { Hemorrhagic } \\
\text { feces }^{\text {b) }}\end{array}$} & \multirow{2}{*}{$\begin{array}{l}\text { Oocysts shec } \\
\text { /chicken } \\
\left(\times 10^{6}\right)^{\mathrm{c})}\end{array}$} & \multirow{2}{*}{ Lesion score ${ }^{\mathrm{d})}$} \\
\hline & & $\begin{array}{c}\text { Initial } \\
\left(2 \times 10^{3}\right)\end{array}$ & $\begin{array}{c}\text { Challenge } \\
\left(1 \times 10^{5}\right)\end{array}$ & & & & & & \\
\hline Control & - & - & - & 6 & 0 & $10.6 \pm 0.8$ & - & 0 & 0 \\
\hline Challenge & - & - & + & 6 & 1 & $8.5 \pm 1.4$ & ++ & 42.0 & +4.0 \\
\hline Initial infection & - & + & - & 6 & 0 & $11.7 \pm 1.7$ & - & 0 & 0 \\
\hline Initial + challenge & - & + & + & 6 & 0 & $11.0 \pm 0.7$ & + & 40.0 & +3.0 \\
\hline SCE (3) + initial & + & + & - & 6 & 0 & $15.9 \pm 0.4^{*}$ & - & 0 & 0 \\
\hline SCE (3) + initial + challenge & + & + & + & 6 & 0 & $13.9 \pm 0.9^{*}$ & + & 3.3 & +2.0 \\
\hline
\end{tabular}

a) Mean \pm standard error.

b) +: Transient hemorrhage; ++: continuous hemorrhage from day 5 to day 7 post infection.

c) Values represent mean oocyst numbers in pooled feces of each group.

d) Values represent mean lesion scores of each group.

* $\mathrm{P}<0.01$, compared to control, challenge and initial + challene groups.

Table 4. Relative proportions (RP) of cells positive for marker antigens in intestinal leukocytes (IL) of chickens orally administered SCE and infected with E. tenella oocysts (Experiment 2)

\begin{tabular}{|c|c|c|c|c|c|c|c|c|c|}
\hline \multirow[b]{2}{*}{ Group } & \multirow[b]{2}{*}{ SCE } & \multicolumn{2}{|c|}{ E. tenella } & \multicolumn{6}{|c|}{ RP (\%) of surface marker antigen positive cells $s^{a}$} \\
\hline & & $\begin{array}{c}\text { Initial } \\
\left(2 \times 10^{3}\right)\end{array}$ & $\begin{array}{l}\text { Challenge } \\
\left(1 \times 10^{5}\right)\end{array}$ & BU- $1 \mathrm{a}^{+}$ & $\mathrm{CD}^{+}$ & $\mathrm{CD} 8^{+}$ & $\mathrm{TCR}^{+}$ & $\mathrm{TCR}^{+}$ & $\mathrm{TCR}^{+}$ \\
\hline Control & - & - & - & 11.8 & 10.2 & 34.1 & 12.5 & 16.5 & 12.5 \\
\hline Challenge & - & - & + & 5.7 & 3.7 & 50.7 & 23.5 & 19.5 & 18.5 \\
\hline Initial infection & - & + & - & 14.4 & 21.0 & 35.9 & 13.4 & 26.5 & 10.5 \\
\hline Initial + challenge & - & + & + & 11.0 & 12.8 & 55.0 & 18.0 & 32.0 & 12.7 \\
\hline SCE (3) initial & + & + & - & 24.5 & 10.5 & 35.4 & 28.8 & 15.5 & 9.3 \\
\hline SCE (3) + initial + challenge & + & + & + & 15.8 & 7.5 & 49.5 & 36.9 & 19.7 & 18.5 \\
\hline
\end{tabular}

a) RP was examined on day 8 after challenge. Values represent the mean PR of 3 chickens in each group.

numbers and titers of responding chickens producing antibodies to BA in the first and second responses.

Gain in body weight, oocyst shedding and lesion scores in Experiment 2: All chickens except the three groups of control, initial infection and SCE (3) + initial in Experiment 2 were challenged with $E$. tenella oocysts $\left(1 \times 10^{5}\right)$. Challenged chickens showed retarded growth as determined by sharply decreased body weight gain/day $(8.5 \pm 1.4 \mathrm{~g} /$ day $)$ as shown in Table 3. Severe and continuous hemorrhages in feces and hemorrhagic feces around the cloaca were also observed in those chickens. In addition, challenged group and initially infected + challenged group shed a large number of oocysts in the feces/chicken on days 6 to $7\left(42 \times 10^{6}\right.$ and $40 \times 10^{6}$, respectively) after challenge infections with typical gross lesions including mucosal edema, severe hemorrhagic intestinal inflammation, gray-white to milky yellow sausage-like structures composed of oocysts, necrotic cells, red blood cells and mucous filling the intestinal lumen and necrosis of the cecum and lower parts of small intestine (lesion score, +4 and +3 , respectively). On the other hand, chickens administered SCE and initially infected with oocysts showed improved body weight gain/day (13.9 \pm 0.9 $\mathrm{g}$ /day), milder hemorrhages and less number of oocysts (3.3 $\times 10^{6}$ ) shed in the feces and mild intestinal inflammation with lower lesion score $(+2)$ after challenge, when compared with the described two groups (Table 3).
RP of surface marker antigens: The results concerning the mean RP in IL from 3 chickens in each group are summarized in Table 4. Chickens challenged with E. tenella oocysts showed decreased RP of $\mathrm{Bu}-1 \mathrm{a}^{+}$and $\mathrm{CD}^{+}$cells $(3.7 \%)$, as compared to control $(11.8 \%$ and $10.2 \%$, respectively). On other hand, the RP of Bu- $1 \mathrm{a}^{+}$cells and $\mathrm{CD} 4^{+}$ cells in SCE (3) + initial + challenge group were $15.8 \%$ and $7.8 \%$, respectively, suggesting that oral administration of SCE just before initial infection with oocysts improved these decreased RP in IL of E. tenella-challenged chickens. Furthermore an apparent increase in the RP of TCR $1^{+}$cells was shown in chicken groups administered SCE, SCE (3) + initial and SCE (3) + initial + challenge, when compared to that of chickens not administered SCE.

Histopathology: As showed in Fig. 1, a lot of schizonts were observed in the cecal mucosa of challenged chickens (Fig. 1A) and initially infected + challenged chickens (Fig. 1B). On the other hand, very few schizonts were observed in cecal sections from SCE (3) + initial + challenge chickens (Fig. 1C).

\section{DISCUSSION}

The goal of the experiments in the present study was to determine the effects of oral administration of SCE on main variables associated with pathology caused by E. tenella 

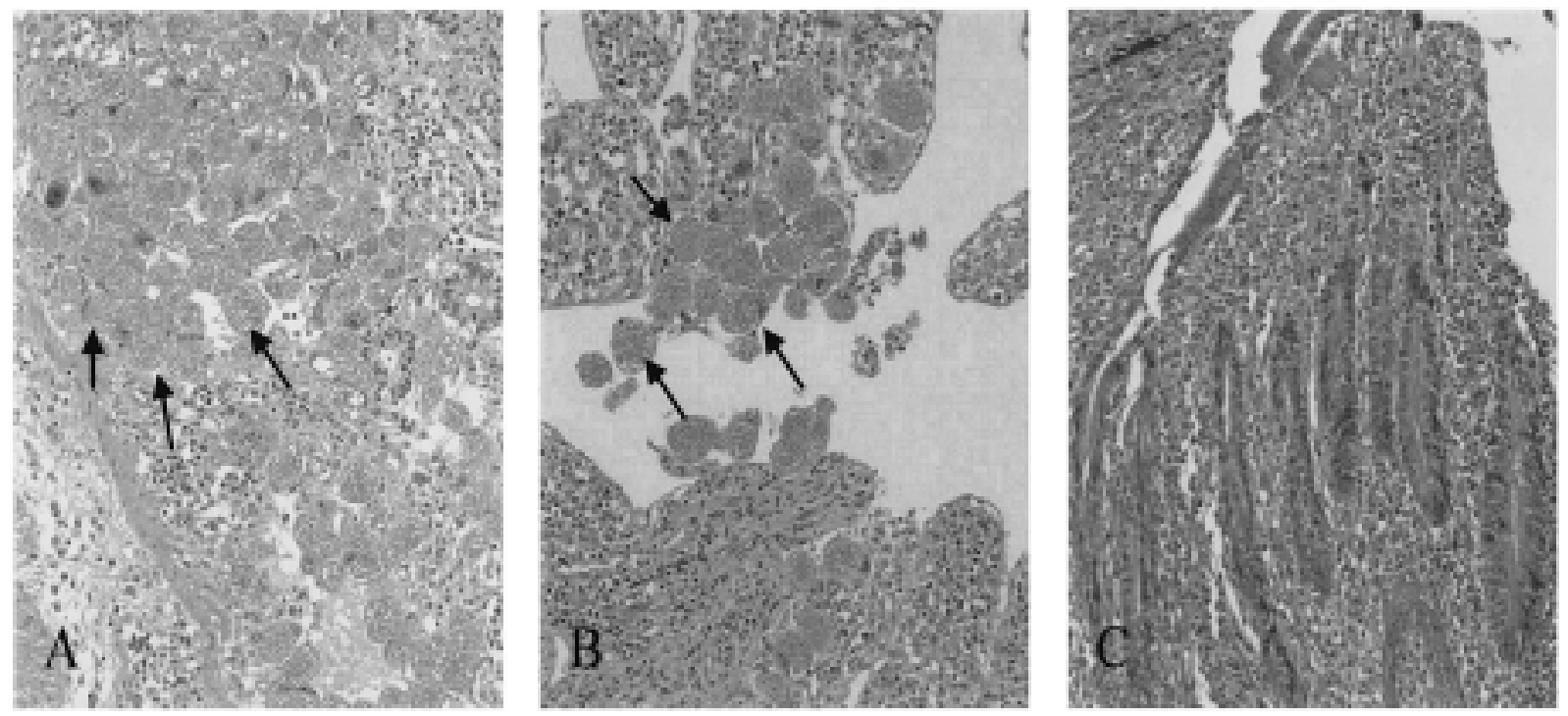

Fig. 1. Histology of the ceca of 5 -week-old chickens challenged with $E$. tenella sporulated oocysts $\left(1 \times 10^{5}\right)(\mathrm{HE}$ stain, $\times 100)$. A) A lot of schizonts $(\rightarrow)$ in the cecal mucosa of challenged chickens, B) many schizonts $(\rightarrow)$ in the cecal mucosa of initially infected + challenged chickens and C) no schizonts in the cecal mucosa of SCE + initially infected + challenged chickens.

infection in chickens including mortality, body weight gain, the degree of hemorrhage in feces, oocyst shedding, lesion score and immune responses. The body weight gain/day significantly decreased after challenge with $E$. tenella oocysts. Reduced body weight gain is a major contributor to production of loss that accompanies coccidial infection in young chickens because inflammatory immune responses divert energy from growth which may affect the weight gain [13]. Oral administration of SCE significantly improved body weight gain per day in initially infected chickens and initially infected + challenged chickens. These results confirmed our previous results concerning the growth-promoting effects of SCE in chickens [5, 6]. The improving effects of SCE on body weight gain and decreasing the mortality in chickens after E. tenella oocyst infection may be associated with its protective effects. Youn and Noh [29] reported that administration of herb extracts improved the survival rate and body weight gain in chickens infected with E. tenella. However, Allen [1] reported that daily oral administration of L-arginine $(500 \mathrm{mg} / \mathrm{kg})$ did not increase the body weight gain but significantly reduced oocyst shed from $E$. tenellainfected chickens than infected control group. The body weight gain/day, hemorrhages and oocyst shedding in feces and lesion scores were investigated during 1 week after challenge with E. tenella oocysts. Hemorrhages in feces of almost all experimental groups, except the uninfected control group, were seen during 5-7 days after infection with $E$. tenella oocyst. But the extent of hemorrhage in feces of chickens administered SCE and initially infected with oocysts was milder than that of other infected groups. The oocyst output in SCE-administered + initially infected + challenged chickens $\left(3.3 \times 10^{6} /\right.$ chicken $)$ was lower than that of challenged group and initially infected + challenged group (42 and $40 \times 10^{6} /$ chicken, respectively). The lesion scores in the SCE + initially infected + challenged group $(+2)$ improved better than those of challenged group and initially infected + challenged group $(+4$ and +3 , respectively). These results indicated a protective effect of SCE on $E$. tenella infection.

The antibody responses against SRBC and BA significantly increased in both first and second responses in chickens orally administered SCE and initially infected with oocysts, when compared with those of uninfected control and initially infected chickens. These results also confirmed our previous findings that oral administration of SCE significantly increased the antibody responses against SRBC, BA and Salmonella enteritidis (SE) and also maintained higher antibody titers than control chickens [5], suggesting the stimulatory effects of SCE on antibody production. The enhancing effects of SCE on humoral immune responses may affect local mucosal immune responses which may correspond with the onset of specific immunity to E. tenella infection. These results are in agreement with those of $\mathrm{Li}$ et al. $[15,16]$ reported the activation of classical complement pathway by a polysaccharide from sugar cane extracts and its interaction with immunoglobulins. Parmentier et al. [20] reported immune responses and resistance to Eimeria acervulina of chickens divergently selected for antibody response to SRBC.

Flow cytometric analysis of cecal tonsil lymphocytes showed decreased relative proportions of $\mathrm{Bu}-1 \mathrm{a}^{+}$and $\mathrm{CD} 4^{+}$ cells in IL of challenged chickens. Oral administration of SCE with oocysts of E. tenella improved these decreased proportions in IL of challenged chickens with $E$. tenella oocysts, indicating the stimulatory effects of SCE on the local mucosal immunity. It is generally believed that $\mathrm{CD}^{+}$ 
cells are important to develop help during antibody responses, but $\mathrm{CD} 4^{+}$cells also provide help during induction of cytotoxic responses $[17,25,28]$. Using the murine model system for protozoan infection, the importance of $\mathrm{CD}^{+}$ cells has been reported in the control of infection with $E$. tenella $[24,25]$ and Toxoplasma gondii $[10,11]$. Stimulation of antibody responses to SRBC and BA in chickens orally administered SCE and initially infected with oocysts and improved relative proportions of $\mathrm{Bu}-1 \mathrm{a}^{+}$and $\mathrm{CD} 4^{+}$cells in IL suggested that administration of SCE with a low dose of oocysts played a role in the development of protective immunity against oocyst-reinfection by interacting with lymphocytes. The importance of lymphocytes in immune responses to coccidia has been reported in chickens [23]. The spleen cells and peripheral blood lymphocytes from immune chickens are capable of transferring the resistance against the infection to naive recipients. Furthermore, the treatment of chickens with immunosuppressive agents enhanced the severity of coccidiosis. Isobe and Lillehoj [9] reported that dexamethasone-treated chickens showed reduced $\mathrm{T}$-cell proliferation, reduced interferon production and increased susceptibility to Eimeria infection. It was reported that cane sugar factors induced in vivo protective responses against Pseudomonas aeruginosa and Proteus mirabilis [21]. Youn and Noh [29] reported anticoccidial effects of herbal extracts on E. tenella infection. In the present study oral administration of SCE with E. tenella oocysts was found to show more effective improvement after challenge than challenged group and initially infected + challenged group on the basis of survival rate, gain in body weight, hemorrhages and oocyst shedding in feces and lesion scores.

Histopathological examination revealed that chickens received SCE with initial infection showed lower numbers of schizonts, gametocytes and oocysts in the cecum after challenge than any other infected groups (even if initially infected with $E$. tenella oocysts). The lack of parasite development in cecal tissues, enhanced immune responses and improved relative proportions of $\mathrm{Bu}-1 \mathrm{a}^{+}$and $\mathrm{CD} 4^{+}$cells in IL of chickens orally administered SCE and initially infected with oocysts indicated that these birds had mounted protective immune responses which may prevent invasion and development of sporozoites in the cecal tissue after challenge. It has been reported that avian humoral immunity in the intestinal tract is mediated via secretion of antibody by plasma cells located within the gut lamina propria into the intestinal lumen [1, 18]. Vervelde et al. [28] reported the major role of intestinal leukocytes in protective immunity following E. tenella infection. The mechanism by which oral administration of SCE results in reduction of pathological lesions in E. tenella-infected chickens remains open. Further basic studies including the interaction between SCE and intestinal immune cells are needed.

Taken together, these results suggest that inoculation of SCE with E. tenella oocysts into the crop induces protective immunity against $E$. tenella infection in chickens. The protective effects of SCE-administration on local mucosal as well as systemic immune responses may inhibit the invasion and/or natural development of the parasites.

\section{REFERENCES}

1. Allen, P. C. 1999. Effects of daily oral doses of L-arginine on coccidiosis infections in chickens. Poult. Sci. 78: 1506-1509.

2. Choi, K. D., Lillehoj, H. S. and Zalenga, D. S. 1999. Changes in local INF- $\gamma$ and TGF- $\beta 4$ mRNA expression and intraepithelial lymphocytes following Eimeria acervulina infection. Vet. Immunol. Immunopathol. 71: 263-275.

3. Conway, D. P. 1979. Examination of lesions and lesion scoring: pp. 17-36. In: "Poultry coccidiosis Diagnostotic and Testing procedures" Pfizer, International Inc., New York, 10017, U.S. A.

4. Dutta, G. P., Mohan, A. and Tripathi, R. 1990. Study of the gametocidal/ sporontocidal action of qinghaosu (artemisinin) by electron microscopy. J. Parasitol. 76: 849-852.

5. El-Abasy, M., Motobu, M., Sameshima, T., Koge, K. and Hirota, Y. 2003. Adjuvant effects of sugar cane extracts (SCE) in chickens. J. Vet. Med. Sci. 65: 117-119.

6. El-Abasy, M., Motobu, M., Shimura, K., Na, K-J., Kang, C-B., Koge, K., Onodera, T. and Hirota, Y. 2002. Immunostimulating and growth-promoting effects of sugar cane extract (SCE) in chickens. J. Vet. Med. Sci. 64: 1061-1063.

7. Erf, G. F., Bottje, W. G., Bersi, T. K., Headrick, M. D. and Fritts, C. A. 1998. Effects of dietary vitamin E on the immune system in broilers: Altered proportions of CD4 T cells in the thymus and spleen. Poultry Sci. 77: 529-537.

8. Hirota, Y., Suzuki, T. and Bito, Y. 1980. The development of unusual B-cell functions in the testosterone-propionate-treated chicken. Immunology 39: 29-36.

9. Isobe, T. and Lillehoj, H. S. 1993. Dexamethasone suppresses T cell-mediated immunity and enhances disease susceptibility to Eimeria mivati infection. Vet. Immunol. Immunopathol. 39: 431-446.

10. Johnson, L. L. and Sayles, P. C. 2002. Deficient humoral responses underlie susceptibility to Toxoplasma gondii in CD4-deficient mice. Infect. Immun. 70: 185-191.

11. Kang, H. J., Remington, J. S. and Suzuki, Y. 2000. Decreased resistance of B cell-deficient mice to infection with Toxoplasma gondii despite unimpaired expression of INF- $\gamma$, TNF- $\alpha$, and inducible nitric oxide synthase. J. Immunol. 164: 26292634.

12. Kawazoe, U. and Fabio, J. D. 1994. Resistance to diclazuril in field isolates of Eimeria species obtained from commercial broiler flocks in Brazil. Avian Pathol. 23: 305-311.

13. Klasing, K. C., Laurin, D. E., Peng, R. K. and Fry, D. M. 1987. Immunologically mediated growth depression in chickens: Influence of feed intake, corticosterone and interleukin-1. Nut. Immunol. 117: 1629-1637.

14. Laurent, F., Mancassola, R., Lacroix, S., Menezes, R. and Naciri, M. 2001. Analysis of chicken mucosal immune response to Eimeria tenella and Eimeria maxima infection by quantitative reverse transcription-PCR. Infect. Immun. 69: $2527-2534$.

15. Li, X. Y. and Vogt, W. 1982. Activation of the classical complement pathway by a polysaccharide from sugar cane. Immunopharmacology 5: 31-38.

16. Li, X. Y., Nolte, R. and Vogt, W. 1983. Natural antibodies against a polysaccharide (Bo) from sugar cane mediate its complement-activating effect. Immunobiology 164: 110-117. 
17. Lillehoj, H. S. 1998. Role of T lymphocytes and cytokines in coccidiosis. Int. J. Parasitol. 28: 1071-1081.

18. Lillehoj, H. S. and Choi, K. D. 1998. Recombinant chicken interferon-gamma- mediated inhibition of Eimeria tenella development in vitro and reduction of oocyst production and body weight loss following Eimeria acervulina challenge infection. Avian Dis. 42: 307-314.

19. Liou, C-T, Wang, J.-S. and Ooi, H.-K. 2001. Immunization against ciccidiosis in phesants with low-dose live sporulated oocysts of Eimeria colchici. Avian Pathol. 30: 283-295.

20. Parmentier, H. K., Abuzeid, S. Y., Reilingh, G. D., Nieuwland, M. G. and Graatt, E. A. 2001. Immune response and resistance to Eimeria acervulina of chickens divergently selected for antibody responses to sheep red blood cells. Poult. Sci. 80: 894900.

21. Pryce, M. J., Aston, W. P. and Chadwick, J. S. 1990. Cane sugar factor as an inducing agent of immunity in Galleria mellonella. Dev. Comp. Immunol. 14: 369-378.

22. Riley, D. and Fernando, M. A. 1988. Eimeria maxima (Apicomplexa): A comparison of sporozoite in naive and immune chickens. J. Parasitol. 74: 103-110.

23. Rose, M. E. and Hesketh, P. 1982. Immunity to coccidia in chickens: Adoptive transfer with peripheral blood lymphocytes and spleen cells. Parasite Immunol. 4: 171-185.

24. Rose, M. E., Hesketh, P. and Wakelin, D. 1992. Immune control of murine coccidiosis: $\mathrm{CD} 4^{+}$and $\mathrm{CD} 8^{+} \mathrm{T}$ lymphocytes contribute differentially in resistance to primary and secondary infections. Parasitology 105: 349-354.

25. Rose, M. E., Joysey, H. S., Hesketh, P., Grencis, R. K. and Wakelin, D. 1988. Mediation of immunity to Eimeria vermiformis in mice by $\mathrm{L} \mathrm{T} 4^{+} \mathrm{T}$ cells. Infect. Immun. 56: 1760 1765.

26. Saitoh, Y., Itagaki, H. and Tsunoda, K. 1986. Experimental development of resistance to decoquinate and robenidine in a multiple drug-resistant strain of Eimeria necatrix. Jpn. J. Vet. Sci. 48: 69-74.

27. Vervelde, L., Vermeulen, A. N. and Jeurissen, S. H. M. 1995. Eimeria tenella: Sporozoites rarely enter leukocytes in the cecal epithelium of the chicken (Gallus domesticus). Exp. Parasitol. 81: 29-38.

28. Vervelde, L., Vermeulen, A. N. and Jeurissen, S. H. M. 1996. In situ characterization of leukocyte subpopulations after infection with Eimeria tenella in chickens. Parasite Immunol. 18: 247-256.

29. Youn, H. J. and Noh, J. W. 2001. Screening of the anticoccidial effects of herb extracts against Eimeria tenella. Vet. Parasitol. 96: $257-263$.

30. Yun, C. H., Lillehoj, H. S. and Choi, K. D. 2000. Eimeria tenella infection induces local gamma interferon production and intestinal lymphocyte subpopulation changes. Infect. Immun. 68: 1282-1288. 